\title{
Evaluation of selected immunological parameters and the concentration of vitamin $D$ in children with asthma. Case-control study
}

\author{
AGATA WAWRZYNIAK ${ }^{1}$, AGNIESZKA LIPINSSKA-OPAEKA ${ }^{1}$, ROBERT ZDANOWSKI , \\ SŁAWOMIR LEWICKI ${ }^{2}$, PIOTR MURAWSKI ${ }^{3}$, BOLESŁAW KALICKI
}

'Department of Pediatrics, Nephrology and Allergology, Military Institute of Medicine, Warsaw, Poland

${ }^{2}$ Department of Regenerative Medicine, Military Institute of Hygiene and Epidemiology, Warsaw, Poland ${ }^{3}$ Department of Regenerative Medicine, Military Institute of Hygiene and Epidemiology, Warsaw, Poland

\begin{abstract}
Due to the increased incidence of allergic diseases and emerging effects of unsatisfactory control of asthma, new mechanisms for supervising the immune system should be searched. The aim of the study was to analyze the percentage of CD3, CD4,CD8,CD19,CD16/56, NKT, CD3 anti-HLADR3 and Foxp3 regulatory lymphocytes in patients with asthma. Additionally the correlation between immune parameters, severity of asthma and serum concentration of vitamin D was performed. 25 children diagnosed with asthma were enrolled. Disease severity was assessed with the Asthma Control Test (ACT) and spirometry. The control group consisted of 15 healthy children. Venous blood from each patient was collected on EDTA or on "clott". Phenotypes of lymphocytes were evaluated by flow cytometry. Vitamin D concentration was assessed by chemiluminescent immunoassay (CLIA) technology. There was a significant decrease in the percentage of T regulatory cells $(p<0.006)$ in children with asthma compared to the control group. There were no significant differences in the other investigated immunological parameters. In addition, in asthma group statistically significant decreased of vitamin $D$ concentration $(p<0.04)$ was observed. There were also no significant correlations between vitamin D3 concentration and the course of asthma or percentage of regulatory cells. The results confirmed the role of regulatory $T$ cells in the pathogenesis of asthma. Effects of vitamin $D$ on the severity of the disease has not been proven.
\end{abstract}

Key words: asthma, regulatory T cells (FoxP3), flow cytometry, vitamin D.

(Cent Eur J Immunol 2017; 42 (1): 101-106)

\section{Introduction}

Asthma is the most common chronic disease in children. According to an epidemiological study ECAP (Epidemiology of Allergic Disorders in Poland), including children aged 6-7 and 13-14 years, the occurrence of asthma and wheezing in the largest Polish cities is estimated respectively at $24.5 \%$ and $17 \%$. A smaller percentage was found in the group of children living in village $-16 \%$ (children aged 6-7 years) and 11.2\% (children aged 13-14 years) [1]. The results suggest that Poland is in the group of countries with a high proportion of inhabitants suffering from allergies.

In the classical theory of allergy subpopulation of $\mathrm{Th} 2$ cells is responsible for the excessive immune response that initiates and promotes the development of asthma. Th2 cells synthesizes interleukins IL-4 and IL-13 which stimulate $\mathrm{B}$ cells to produce $\mathrm{IgE}$ antibodies [2]. In contrast, cy- tokines relased from Th1 cells (interferon $\gamma-$ IFN- $\gamma$, tumor necrosis factor $\alpha-$ TNF- $\alpha$ ) inhibit the allergic reaction in the airways. Recent studies indicate the additional populations of immune cells that are involve in the pathogenesis of asthma - Th17 cells and regulatory T cells (Treg). Shi et al. [3] found elevated concentration of Th17 cells and decreased concentration of Treg cells in peripheral blood of patients with asthma.

Regulatory $\mathrm{T}$ cells play a key role in the acquisition of immune tolerance by inhibiting the activity of Th1, Th2 and Th17 cells, basophils, eosinophils and mast cells [4]. Phenotypically regulatory $\mathrm{T}$ cells is a heterogeneous group. We can distinguish a natural regulatory T cells (nTreg) generated during differentiation in the thymus and induced in the peripheral $\mathrm{T}$ cells (iTreg). One of the major subpopulation in peripheral blood is natural Treg lymphocytes with a phenotype: $\mathrm{CD} 4^{+} \mathrm{CD} 25^{\text {high }} \mathrm{CD} 127^{\text {low/-FoxP3 }}{ }^{+}$. FoxP3

Correspondence: Sławomir Lewicki, Department of Regenerative Medicine and Cell Biology, Military Institute of Hygiene and Epidemiology, Kozielska 4, 01-163, Warsaw, Poland, tel. +48 22618531 01, fax +48 22618 531 33, e-mail: lewickis@ gmail.com Submitted: 5.09.2016; Accepted: 3.02.2017 
protein is particularly important because it is responsible for the development and function of Treg [5]. Research in animal models have shown that mutations in gene of the transcription factor lead to a loss of normal function of Treg [6]. Inhibitory effect of regulatory $\mathrm{T}$ cells is associated with expression of multiple cell surface markers such as $\alpha$-chain receptor for IL-2 (CD25) and particle CTLA-4 (CD152).

The results of studies on the impact of vitamin D on the course of asthma and regulatory $\mathrm{T}$ cells are ambiguous. In vitro studies have suggested that vitamin $\mathrm{D}$ might inhibit the bronchial remodeling and exacerbation by decreasing inflammatory response [7]. The impact of vitamin $\mathrm{D}$ on diseases involving a Th1-mediated response has been known. Still, little is known about its impact on Th2 and Treg. It is suggested that $1.25(\mathrm{OH}) \mathrm{D}$ promotes $\mathrm{Th} 2$ and Treg cells [8]. Studies require continuation due to emerging reports of inhibitory effect on these cells [9].

\section{Aim of the study}

The aim of the study was to analyze the percentage of lymphocytes CD3, CD4, CD8, CD19, CD16/56, NKT, CD3 anti-HLADR3 and nTreg in children with asthma. It was also investigated the correlation between studied parameters, severity of asthma and serum concentration of vitamin D.

\section{Material and methods}

\section{Patients}

The study was approved by the Ethics Committees of the Military Institute of Medicine in Warsaw (No. 123/14 consent). The study included children hospitalized in Department of Pediatrics, Nephrology and Allergology. All parents of children qualified to the study were informed of the purpose of the experiments carried out and expressed written consent to participate. The study group consisted of 25 children diagnosed with asthma according to GINA 2014 criteria [10] in stable period of the diseaase. Infections was excluded. All patients were treated by inhaled glucocorticosteroids (children with low daily dose $-22 \%$, moderate daily dose $-56 \%$, high daily dose $-22 \%$ ). Atopy was confirmed by positive skin prick test and elevated concentration of IgE in serum. Children with concomitant other respiratory diseases, defects of the chest and not cooperating in the investigation were excluded. The control

Table 1. The characteristics of the groups

\begin{tabular}{ccc}
\hline & Study group & Control group \\
\hline Number & 25 & 15 \\
\hline Age & $8\left(\mathrm{q}_{25 \%}=6 ; \mathrm{q}_{75 \%}=12\right)$ & $7\left(\mathrm{q}_{25 \%}=5 ; \mathrm{q}_{75 \%}=8\right)$ \\
\hline Gender (F: $\mathrm{M})$ & $8: 17$ & $9: 6$ \\
\hline
\end{tabular}

group represented 15 children without symptoms of allergic disease, infections was excluded. The median age in the test group and the control group were similar. Characteristics of the groups is shown in Table 1.

\section{Severity of asthma}

The degree of asthma control was evaluated by the Asthma Control Test (ACT). This is a test composed of five questions about the incidence of symptoms of the disease, medication use, the impact of the disease on daily activities and self-assessment of disease control.

In each asthma patient spirometry and concentration of nitric oxide in exhaled air (eNO) was evaluated.

Spirometry was performed by Lungtest 1000 apparatus. Study met the conditions for acceptability and reproducibility as recommended by the ATS/ERS. The results were expressed as percentages of predicted values. The normal range was determined based on the dispersion value of the parameter in the healthy population (3-95 percentile).

eNO concentration were measured in Medisoft FeNO analyzer. The generally accepted norm for children is a value of $20 \mathrm{ppb}$ NO. All measurements were performed in the morning on an empty stomach.

\section{Phenotype analysis}

Analysis of lymphocytes phenotypes was performed as previously described [11]. Peripheral blood samples were collected in EDTA-anticoagulated tube. Determination of blood lymphocyte immunophenotype was evalutaed by IMK Plus Kit (BD Biosciences, Poland) after erythocyte lysis (BD FACS Lysing Solution, BD Biosciences, Poland). Stained cells were acquired in flow cytometry (Facs Calibur, BD, Germany). Additionally percentage distributions of white blood cells (lymphocytes, monocytes, granulocytes, neutrophils, eosinophils) was done using CD45, FITC, CD14 PE antibody and FSC/SSC determination. Results of lymphocyte phenotypes are presented as mean percentage of lymphocytes \pm SD.

To characterize natural $\mathrm{T}$ regulatory cells, cells were stained with primary antibodies against CD4-PerCP, CD25-APC, CD127-FITC and FoxP3 PE molecules (BD Bioscence, Poland) or appropriate isotype control. Cells were acquired in flow cytometry. 10000 counts of CD4 PerCP positive cells finished the acquisition. Percentage of nTreg cells (FoxP3 $3^{+}, \mathrm{CD} 25^{\text {high }}, \mathrm{CD} 127^{\text {low/- }}$ ) were counted in $\mathrm{CD} 4$ postive cells.

\section{Serum vitamin D analysis}

Dia-Sorin LIAISON® analyzer (DiaSorin, Italy) was used to determine the concentration of total 25-hydroxyvitamin D. Designed for immunoassay testing, LIAISON® analyzer adopts a "Flash" chemiluminescence technology with a paramagnetic microparticle solid phase (MP). 


\section{Statistical analysis}

The results were statistically analyzed based on software StatSoft, Inc. (2014) STATISTICA (data analysis software system), version 12 . Analyses were initially verified by chart normality and finally using a test of normality Kolmogorov-Smirnov and Lilieforsa. For the evaluation of variables with normal distribution Student's t-test was used. In other cases Mann-Whitney test was used. Correlation analysis was performed using Sperman's factor (variables without normal distribution) or Pearson's factor (variables with normal distribution). $P$ values $<0.05$ were considered as statistically significant.

\section{Results}

\section{Patients}

A statistically significant increase in levels of total IgE antibodies in the study group compared with nonallergic children was noted (average $751 \pm 40 \mathrm{IU} / \mathrm{ml}$ in asthma group vs average $47 \pm 38 \mathrm{IU} / \mathrm{ml}$ in control group; $p<0.000004)$.

\section{Asthma severity}

Based on ACT test, maximum 25 points score (well controlled asthma) was achieved in $32 \%$ of children, result in the range of 20-24 points (partially controlled asthma) in $24 \%$ of children, and $\leq 19$ points (uncontrolled asthma) in $44 \%$ of children (Fig. 1).

Table 2 shows the average values of spirometric parameters and eNO in children with asthma. The Tiffeneau index was lowered and nitric oxide in exhaled air was higher.

\section{Subpopulations of lymphocytes}

Analysis revealed a significant decrease in the percentage of lymphocytes nTreg cells $\mathrm{CD} 4{ }^{+} \mathrm{CD} 25^{\text {high }} \mathrm{CD} 127^{\text {low/- }}$ FoxP3 ${ }^{+}$phenotype $(p<0.006)$ in patients with asthma compared to the control group (Fig. 2).

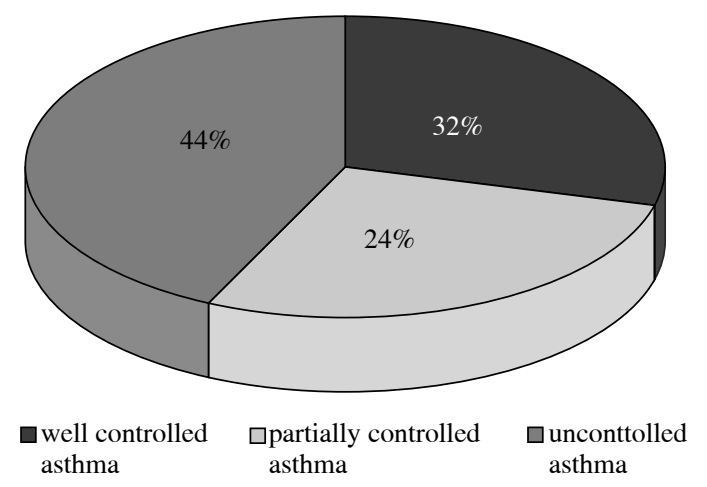

Fig. 1. The degree of asthma control according to the ACT test
There were no statistically significant differences between the other studied immune cells percentages (CD3, CD19, CD4, CD8, CD16/56, NKT, CD3 anti-HLA DR3 phenotype) between the groups (Table 3 ).

\section{Serum vitamin D concentration}

The study revealed significantly lower vitamin D serum concentration in children with asthma compared to the control group $(22.8 \pm 9.62$ vs. $31.4 \pm 9.65 \mathrm{ng} / \mathrm{ml} ; p<0.04)$. Furthermore, in children with asthma we observed lower percentage of patients with normal concentrations of vitamin D. Optimal vitamin D concentration was found in $26 \%$ of asthma children, whereas in the control group - in $67 \%$ of cases. Additionally in asthma group, increased percentage of vitamin D deficient were noted. Percentage values of vitamin D concentrations in both groups are presented in Fig. 3 (distribution of values is statistically significant, $p=0.002)$.

\section{Correlations}

There was no significant correlations between vitamin D serum concentration and percentage of nTreg. There were also no significant relationship between vitamin D concentration and percentage of CD3, CD19, CD4, CD8, CD 16/56, NKT, CD 3 anty-HLA-DR3 in study group (asthma). However, in the control group several correlations among vitamin $\mathrm{D}$ and immune cells percentage were observed. We found a negative correlation between the concentration of vitamin D and the percentage of CD8 cell. It was related with positive correlation of CD4/CD8 ratio $(p<0.05)$ in non-allergic children with vitamin $\mathrm{D}$ concentration. Moreover, a positive correlation between the percentage of CD19 and vitamin D level was found. It was also shown that the percentage of CD3, CD3 and antiHLA-DR3 is negatively correlated with the concentration of vitamin D levels in non-allergic children. However, in control group several correlations among vitamin D and immune cell percentage were observed (Table 4).

Table 2. Results of spirometric parametres and eNO in children with asthma

\begin{tabular}{lc}
\hline Variable & Value (average \pm SD) \\
\hline FVC [\%] & $92.81 \pm 14$ \\
\hline FEV $_{1}[\%]$ & $89.29 \pm 16$ \\
\hline FEV $_{1} / \mathrm{FVC}[\%]$ & $62.50 \pm 21$ \\
\hline PEF [\%] & $79.53 \pm 21$ \\
\hline MEF50 [\%] & $78.35 \pm 21$ \\
\hline eNO [ppb] & $27.67 \pm 26$ \\
\hline
\end{tabular}




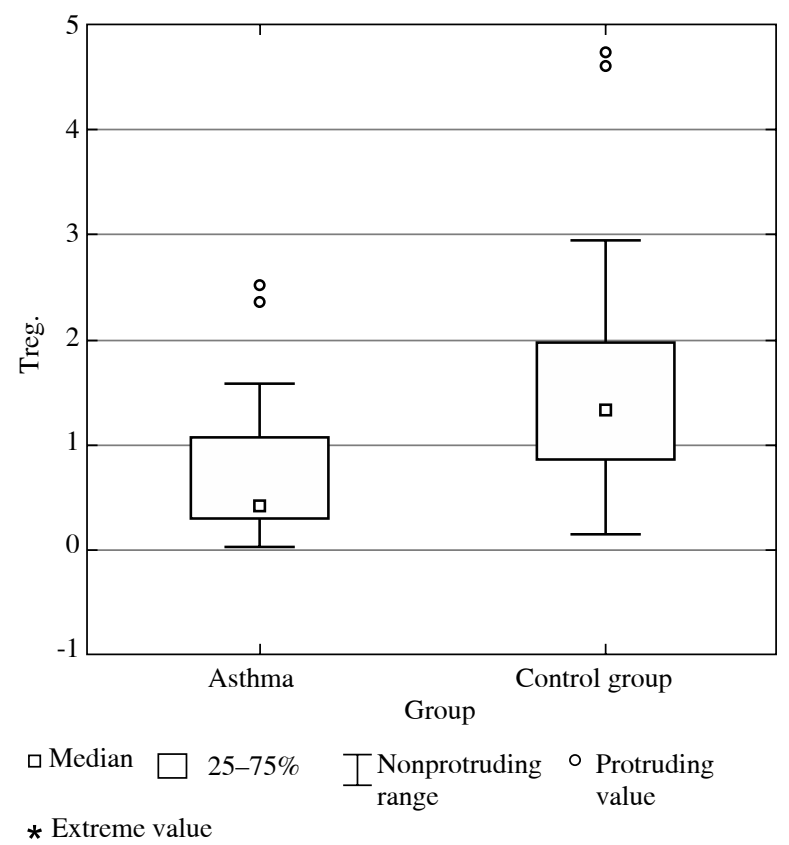

Fig. 2. The comparison of the average percentage of Treg cells in groups

A

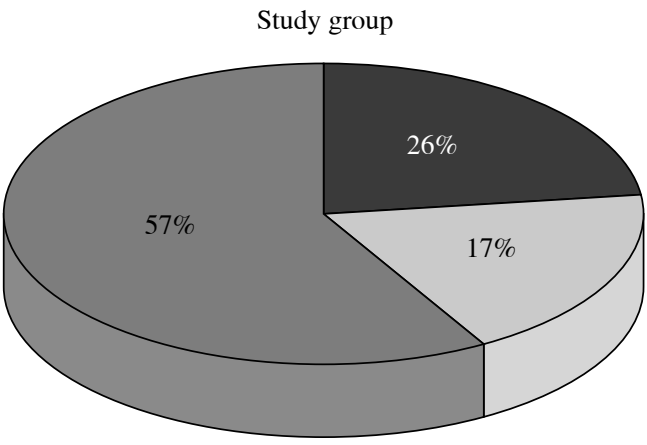

$\begin{array}{lcc}>30 \mathrm{ng} / \mathrm{ml} \text { - optimal } & \square>20-29 \mathrm{ng} / \mathrm{ml}- & \square>20 \mathrm{ng} / \mathrm{ml}- \\ \text { concentration } & \text { insufficiency } & \text { deficiency }\end{array}$

B

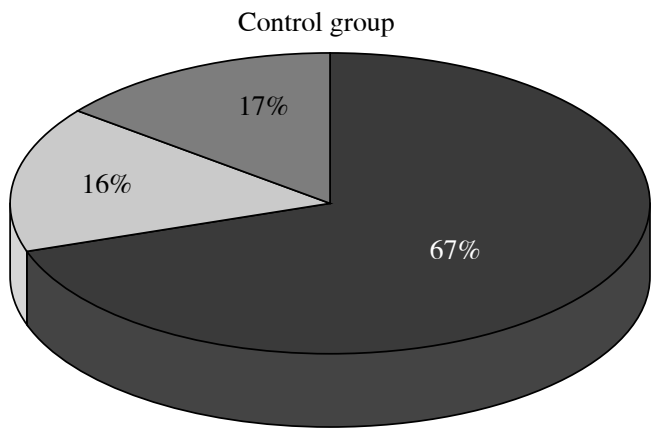

$>30 \mathrm{ng} / \mathrm{ml}$ - optimal $\square>20-29 \mathrm{ng} / \mathrm{ml}-\quad \square>20 \mathrm{ng} / \mathrm{ml}-$ concentration insufficiency deficiency

Fig. 3. The percentage distribution of vitamin D concentration in each group
Table 3. The average percentage of peripheral blood lymphocytes in each group

\begin{tabular}{lccl}
\hline Variable & Study group & Control group & $\boldsymbol{p}$ \\
\hline $\mathrm{CD} 3$ & $66.14 \pm 8$ & $63.70 \pm 6$ & $\mathrm{~ns}$ \\
\hline $\mathrm{CD} 19$ & $15.07 \pm 5$ & $17.08 \pm 6$ & $\mathrm{~ns}$ \\
\hline $\mathrm{CD} 4$ & $34.56 \pm 7$ & $34.13 \pm 5$ & $\mathrm{~ns}$ \\
\hline $\mathrm{CD} 8$ & $30.62 \pm 4$ & $28.63 \pm 8$ & $\mathrm{~ns}$ \\
\hline $\mathrm{CD} 4 / \mathrm{CD} 8$ & $1.07 \pm 0.3$ & $1.29 \pm 0.5$ & $\mathrm{~ns}$ \\
\hline $\mathrm{CD} 16 / 56$ & $9.12 \pm 6$ & $12.60 \pm 5$ & $\mathrm{~ns}$ \\
\hline $\mathrm{NKT}$ & $3.18 \pm 2$ & $2.68 \pm 2$ & $\mathrm{~ns}$ \\
\hline $\mathrm{CD} 3$ anti-HLA & $6.50 \pm 3$ & $6.34 \pm 4$ & $\mathrm{~ns}$ \\
DR3 & & & \\
\hline
\end{tabular}

Table 4. Correlations between immunology parameters and vitamin D in study and control group (marked correlation coefficients are significant with $p<0.05$ )

\begin{tabular}{lcc}
\hline Correlated parameters & Study group & $\begin{array}{c}\text { Control } \\
\text { group }\end{array}$ \\
\hline Vitamin D \& CD3 & -0.095 & -0.706 \\
\hline Vitamin D \& CD19 & 0.149 & 0.727 \\
\hline Vitamin D \& CD4 & -0.130 & 0.364 \\
\hline Vitamin D \& CD8 & -0.138 & -0.846 \\
\hline Vitamin D \& CD4/CD8 ratio & -0.025 & 0.713 \\
\hline Vitamin D \& CD16/56 & -0.040 & -0.189 \\
\hline Vitamin D \& NKT & -0.234 & -0.350 \\
\hline Vitamin D \& CD3 anti-HLA DR3 & 0.174 & -0.748 \\
\hline
\end{tabular}

There was no significant correlation between vitamin $\mathrm{D}$ levels and the severity of the disease (based on questionnaire ACT, spirometry and eNO).

\section{Discussion}

Literature data indicates that the regulatory cells may impact, in directly or indirectly way, several immunological components of allergic inflammation cascade and asthma. The cells affect the phase of sensitization to an allergen, promoting the development and consolidation of inflammation, develop hyperactivity and airway remodeling [12]. It has been also shown that in allergic diseases concentration or functionality of Treg cells is disturbed. In present work we also observed that relationship. The percentage of natural $\mathrm{T}$ regulatory Foxp 3 in peripheral blood was lower in children with asthma in comparison to non-asthma children. It is consistent with our preliminary studies [11] and other researchers observations. Abnormalities in the number of blood peripheral regulatory $\mathrm{T}$ cells in asthma patients may be the results of development inhi- 
bition at the transcriptional level. Xue et al. [13] observed a reduction in expression of Foxp3 mRNA in peripheral blood mononuclear cells isolated from patients with asthma. Moreover, Lee et al. [14] reported a decreased level of $\mathrm{CD} 4{ }^{+} \mathrm{CD} 25^{+}$in children with asthma or rhinitis, although at the same time showed that the level of cells increases with the severity of the allergic disease. It was connected with a higher expression of Foxp3 protein which may explain possible effect of glucocorticoid treatment in patients with more severe disease. It is believed that the malfunction of Treg population promotes the development of sensitization to allergens. Sensitization usually occurs during early childhood or even before birth. Regulatory T cell can inhibit the stage of sensitization and limit the development of asthma [15]. Proper impact on the regulatory T-cells may alleviate or completely reduce symptoms of allergy and asthma especially at the beginning of diseases development. However, the findings of other researchers suggest that the relationship between allergic diseases and deficit of regulatory cells is not so easy. Shi et al. [16] found no difference in the number of lymphocytes nTreg between healthy subjects and patients with asthma or atopy. Furthermore, authors noted an increase of $\mathrm{CD} 4{ }^{+} \mathrm{CD} 25^{+}$cells population in the exacerbations of asthma, which have not been observed in patients with stable disease.

In recent years the impact of vitamin D on allergic diseases is emphasized. It is suggested that vitamin D inhibits immune responses involving Th1 and Th17 cells, while its impact on Th2 and Treg cells is not clear.

In our study, the average vitamin D concentration was decreased in children with asthma compared to the control group. Peroni et al. [17] in study aimed to assess the effects of vitamin D on the incidence of asthma, obtained divergent results. Authors formulated two different hypotheses what called the "paradox of vitamin D". This paradox means that both deficiency as well as excessive supplementation of vitamin D may be associated with an increased risk for atopic asthma and other allergic diseases [17]. The authors of the meta-analysis of the epidemiological relationship between low levels of vitamin D in the blood serum and diagnosis of asthma in children, concluded that the available evidence suggests a potential association, but high-quality studies are needed to answer this question [18].

It is believed that vitamin D deficiency may be associated with a worse respiratory tract function. In present study we did not observe the correlation between vitamin D levels and the severity of the asthma disease (using the ACT questionnaire, spirometry and nitric oxide concentration in exhaled air). Different results were obtained in a pilot study by Zaragoza-Buxo et al. [19], who observed that higher levels of vitamin $\mathrm{D}$ were associated with higher scores ACT questionnaire. Gupta et al. [20] analyzed the correlation between levels of vitamin D in the blood and the course of asthma severity in children. Authors simi- larly demonstrated a positive correlation between serum $1.25(\mathrm{OH}) \mathrm{D}$, parameters of lung function $\left(\mathrm{FEV}_{1}, \mathrm{FVC}\right)$ and the test results in Asthma Control Test. In opposite, it was observed a negative correlation between serum 1.25(OH)D and episodes of acute illness, doses of inhaled corticosteroids and thickening of the bronchial smooth muscle layer. Sutherland et al. [21] reported that higher levels of vitamin $\mathrm{D}$ was positively correlated with better lung function, with a $22.7 \pm 9.3 \mathrm{ml}$ (mean $\pm \mathrm{SE}$ ) increase in $\mathrm{FEV}_{1}$ for each nanogram per milliliter of vitamin $\mathrm{D}$.

In 2014 VIDA clinical trial results have been published [22]. The aim of the study was to evaluate whether vitamin D supplementation improves clinical efficacy of inhaled glucocorticoids in patients with symptoms of asthma. This was a prospective, randomized double-blinded, placebo-controlled study. It included 408 adults with asthma and levels of vitamin D in the blood serum below $30 \mathrm{ng} /$ $\mathrm{ml}$. It has been shown that vitamin D supplementation did not reduce the number of exacerbations in patients with asthma.

Vitamin D receptor (VDR) is expressed on T and B lymphocytes, monocytes and antigen presenting cells (APC). Vitamin D affects the proliferation, differentiation and function of the immune system [23]. However the effect on vitamin D3 on the development of Treg cells is still unknown. It seems that calcitriol may promotes Treg development. In our study there was no correlation between levels of vitamin $\mathrm{D}$ in the serum of children with a percentage of nTreg cells. In opposite, Maalmi et al. [24] reported significant positive correlation between serum $25(\mathrm{OH}) \mathrm{D}$ and the number of $\mathrm{CD} 25^{+} \mathrm{Foxp}^{+}$cells and a negative correlation between serum vitamin D and number of Th17 cells. Ghoreishi et al. [25] in a study conducted in mice, showed a higher production of Treg cells in group supplemented with vitamin $\mathrm{D}$ analogues (calcipotriol) followed by immunization with ovalbumin. The induction of FoxP3 ${ }^{+}$Treg by UV irradiation was VDR dependent, as UV-irradiated $\mathrm{VDR}^{-/}$mice failed to show any increase in this subset.

The impact of vitamin D on B lymphocytes is widely discussed in recent years. We observed a positive correlation between serum concentration of vitamin D and the percentage of CD19 in healthy children. In turn, Chen et al. [26] show that $1.25(\mathrm{OH}) 2 \mathrm{D} 3$ has potent direct effects on $\mathrm{B}$ cell responses, inhibiting proliferation, generation of classswitched memory B cells, plasma cell differentiation, and immunoglobulin production. However, the response of $B$ cells to $1.25(\mathrm{OH}) \mathrm{D}$ is dependent on the expression of VDR receptors on their surface and the ability to degrade active form of vitamin $\mathrm{D}$. The differences in our and Chen study may be due to the small size of the group.

In our study we observe a negative correlation between vitamin D and CD8+ cells. Similar results were obtained by Hwang et al. [27]. They found a significant inverse correlation between $25(\mathrm{OH}) \mathrm{D}$ levels and the frequency of na- 
ive CD8 cells. This study was conducted on older women (>60 years old).

\section{Conclusions}

The results confirmed the role of regulatory $\mathrm{T}$ cells in the pathogenesis of asthma. Effects of vitamin $\mathrm{D}$ on the severity of the disease has not been proven. The study need to be continued due to the small size of the group.

This research was supported by Military Institut of Medicine grant 1/8865 (323).

The authors declare no conflict of interests.

\section{References}

1. Epidemiology of Allergic Disorders in Poland. Available from: http://www.ecap.pl.

2. Barnes P (2008): Immunology of asthma and chronic obstructive pulmonary disease. Nat Rev Immunol 8: 183-192.

3. Shi Y, Shi G, Wan H (2011): Coexistence of Th1/Th2 and Th17/Treg imbalance in patients with allergic asthma. Chin Med J 124: 1951-1956.

4. Akdis C, Akdis M (2009): Mechanisms and treatment of allergic disease in the big picture of regulatory T cells. J Allergy Clin Immunol 123: 735-746.

5. Yagi H, Nomura T, Nakamura K, et al. (2004): Crucial role of FoxP3in the development and function of human CD25+CD4+ regulatory cells. Int Immunol 16: 1643-1656.

6. Fontenot J, Gavin M, Rudensky A (2003): Foxp3 programs the development and function of CD4+CD25+ regulatory $\mathrm{T}$ cells. Nat Immunol 4: 330-336.

7. Iqbal SF, Freishtat RJ (2011): Mechanism of action of vitamin $\mathrm{D}$ in the asthmatic lung. J Investig Med 59: 1200-1202.

8. Pawlak J, Doboszyńska A (2014): Witamina D w chorobach alergicznych. Postepy Hig Med Dosw 68: 1152-1170.

9. Baroni E, Biffi M, Benigni F, et al (2007): VDR-dependent regulation of mast cell maturation mediated by 1,25 -dihydroxyvitamin D3. J Leukoc Biol 81: 250-262.

10. GINA REPORT 2014, Global strategy for asthma management and prevention. Updated December 2011. Available from: http://www.ginasthma.org/GINA-Report-Global-Strategy-for-AsthmaManagement-and-Prevention-Raport.

11. Kalicki B, Lewicki S, Stankiewicz W, et al. (2013): Examination of correlation between vitamin D3 (25-OHD3) concentration and percentage of regulatory $\mathrm{T}$ lymphocytes (FoxP3) in children with allergy symptoms. Centr Eur J Immunol 38: 70-75.

12. Kon O, Kay A (1999): T cells and chronic asthma. Int Arch Allergy Immunol 118: 133-135.

13. Xue K, Zhou Y, Xiong S, et al. (2007): Analysis of CD4+CD25+regulatory T cells and Foxp3 mRNA in the peripheral blood of patients with asthma. J Huazhong Univ Sci Technolog Med Sci 27: 31-33.

14. Lee J, Yu H, Wang L, et al. (2007): The levels of CD4+CD25+ regulatory $\mathrm{T}$ cells in paediatric patients with allergic rhinitis and bronchial asthma. Clin Exp Immunol 148: 53-63.

15. Nouri-Aria K, Durham S (2008): Regulatory T cells and allergic disease. Inflamm Allergy Drug Targets 7: 237-252.
16. Shi H, Li S, Xie Z, et al. (2004): Regulatory CD4+CD25+ T lymphocytes in peripheral blood from patients with atopic asthma. Clin Immunol 113: 172-178.

17. Peroni D, Bonomo B, Casarotto S, et al. (2012): How changes in nutrition have influenced the development of allergic diseases in childhood. Ital J Pediatr 38: 22, doi: 10.1186/18247288-38-22.

18. Rajabbik M, Lotfi T, Alkhaled L, et al. (2014): Association between low vitamin $\mathrm{D}$ levels and the diagnosis of asthma in children: a systematic review of cohort studies. Allergy Asthma Clin Immunol 10: 31, doi: 10.1186/1710-1492-10-31.

19. Zaragoza Buxo J, Perez L, Bredy R (2012): Relation between serum vitamin D level and asthma. Bol Asoc Med P R 104: 12-16.

20. Gupta A, Sjoukes A, Richards D, et al. (2011): Relationship between serum vitamin $\mathrm{D}$, disease severity, and airway remodeling in children with asthma. Am J Respir Crit Care Med 184: 1342-1349.

21. Sutherland ER, Goleva E, Jackson LP, et al. (2010): Vitamin $\mathrm{D}$ levels, lung function, and steroid response in adult astma. Am J Respir Crit Care Med 181: 699-704.

22. Castro M, King T, Kunselman S, et al. (2014): Effect of vitamin D3 on asthma treatment failures in adults with symptomatic asthma and lower vitamin D levels: the VIDA randomized clinical trial. JAMA 311: 2083-2091.

23. Guillot X, Semerano L, Saidenberg-Kermanach N, et al. (2010): Vitamin D and inflammation. Joint Bone Spine 77: 552-557.

24. Maalmi H, Berrades A, Tangour E, et al. (2012): The impact of vitamin D deficiency on immune T cells in asthmatic children: a case-control study. J Asthma Allergy 5: 11-19.

25. Ghoreishi M, Bach P, Obst J, et al. (2009): Expansion of antigen-specific regulatory $\mathrm{T}$ cells with the topical vitamin $\mathrm{d}$ analog calcipotriol. J Immunol 182: 6071-6078.

26. Chen S, Sims GP, Chen XX, et al. (2007): Modulatory effects of 1,25-dihydroxyvitamin D3 on human B cell differentiation. J Immunol 179: 1634-1647.

27. Hwang Y, Hsu H, Lim F, et al. (2013): Increased vitamin $\mathrm{D}$ is associated with decline of nadve, but accumulation of effector, CD8 T cells during early aging. Advances in Aging Research, 2: 72-80. 